\title{
Case Study of Reactor Containment Building Construction in Nuclear Power Plant
}

\author{
Hyomin Song1, Sangyong Kim², Yooseok Shin ${ }^{3 *}$, Gwang-Hee Kim \\ ${ }^{1}$ Department of Architectural Engineering, Graduate School of Kyonggi University, Suwon-Si, Korea \\ ${ }^{2}$ Construction Management and Engineering, University of Reading, Reading, UK \\ ${ }^{3}$ Department of Plant \& Architectural Engineering, Kyonggi University, Suwon-Si, Korea \\ Email: ${ }^{*}$ shinys@kgu.ac.kr
}

Received 18 July 2014; revised 19 August 2014; accepted 1 September 2014

Copyright (C) 2014 by authors and Scientific Research Publishing Inc.

This work is licensed under the Creative Commons Attribution International License (CC BY).

http://creativecommons.org/licenses/by/4.0/

cC) (7) Open Access

\begin{abstract}
It is very important to reduce the construction duration of the Reactor Containment Building (RCB) when considering the more than $\mathbf{5 0}$ months on average from concrete placement to completion. Through a case study, this study performs a pre-study for the reduction of construction duration in nuclear power plant project based on construction process of the RCB. The actual data of the case study have been collected and analyze the process and the external wall drawings of the RCB with construction practitioners. As a result of that, it is necessary to modularize the external wall form for equipment hatch and to extend the height of one layer of the external wall form to reduce the construction duration of RCB. The results of this study will be utilized to reduce construction duration of the nuclear power plant.
\end{abstract}

\section{Keywords}

Nuclear Reactor, Nuclear Power Plant, Reactor Containment Building, Form Work

\section{Introduction}

December 27, 2009 was a landmark in Korean construction history, as a Korean consortium won the bid for the construction of a nuclear power plant to United Arab Emirates (UAE). This not only was meaningful for being the first export of a Korean nuclear power plant to another country, but also it puts the spotlight on Korea. The results had prevailed over bids by France and the United States that had handed down nuclear power plant construction technologies to Korea [1].

As the scale of nuclear power market in the world is growing rapidly, the nuclear power plant business has been a pressing issue as a growth engine for Korea, and there is an urgent need for Korea to secure a competitive 
edge in the export of nuclear power plants to other countries. Changes in nuclear power policies are expected in some countries due to the Fukushima nuclear accident of 2011, but the weight of nuclear energy will be increasing in 2035 with the construction of nuclear power plants in India and Russia [2]. IEA (Internetional Energy Agency) provided an outlook of a rapid increase of up to $40 \%$ in energy demand from non-OECD countries including China [3]. In particular, approximately 460 nuclear power plants are planned to be built by 2030 in 40 countries in the world.

Initial construction cost accounts for a large portion of a nuclear power plant construction project, and the construction duration usually takes a long time, so the interest expense represents around $20 \%$ of the total construction cost; for this reason, early commercial operation of a power plant is needed through the reduction of the construction duration to cut the construction cost [4]. However, to reduce the construction duration usually takes more than 50 months on average from concrete placement to completion. Constructability should be improved to shorten the construction duration of the RCB, a key structure in the nuclear power plant. In Korea, diverse studies have been conducted on nuclear power plant construction, the construction management of nuclear power plants, and the design of concrete nuclear power structures and plans for rationalization of construction, however few studies have been performed on the case of the RCB for a nuclear power plant.

Therefore, this study performed case study of the RCB focused on the construction process and duration as a pre-study for the reduction of construction duration in nuclear power plant projects. This study was conducted by collecting data such as process and the external wall drawings to improve constructability of the RCB for a nuclear power plant. In next section, we reviewed previous studies and related literature and the current state of nuclear power plant construction in Korea, and information on the nuclear power plant construction was obtained through data published by KHNP (Korea Hydro \& Nuclear Power), as well as through interviews with practitioners. The importance of this study is discussed and the current state of nuclear power plant construction in Korea is introduced through a theoretical review. In Section 3, the process, construction duration, the sectional drawing of external wall, the construction procedure, workload, and the input of laborers required to construct the RCB for a nuclear power plant are presented. In Section 4, analysis of the data is performed, and the analytical results are described. Finally, the conclusion and a direction for future study are suggested.

\section{Theoretical Review}

\subsection{Literature Review}

On the studies of nuclear power plant construction, Lee Dae-Su (1996) [5] studied an application case of improved constructability focusing on the reduction of the construction duration of nuclear power plants. Jo Yeong-Seok (2002) [6] researched independent construction based on the knowledge accumulated and developed over 30 years since the first nuclear power plant, as well as the reduction effect of the construction power plant construction and improvement of quality. Mun Byeong-Seok (2009) [7] presented a development plan for an EVMS model and a simulation system to examine the concept of EVM technique and domestic and overseas application cases through the literature review. Kim Tae-Hong (2011) [8] studied the design of concrete nuclear power structures and a plan for the rationalization of construction. As of now, there have been almost no studies conducted on the reduction of construction duration of an RCB for a nuclear power plant, despite diverse studies on nuclear power plant construction project. Therefore, this study first reviewed cases of the construction of RCBs, with the aim of improving the constructability of the RCB external wall to achieve a reduction in the duration of construction of a nuclear power plant.

\subsection{The Current State of Nuclear Power Plant Construction in Korea}

Figure 1 shows the current state of nuclear power plant construction. A total of 32 nuclear power plants is in operation or planned to be built in Korea. Table 1 indicates the performance of power generation by plant. Specifically, Hanul Nuclear Power Plant showed the highest power generation, while Hanbit Nuclear Power Plant generated the most nuclear power in terms of accumulated power generation. The total accumulated nuclear power generation of all the nuclear power plants in Korea stands at 2,831,888,209 MWh. Table 2 is the nuclear power generation in Korea between 2003 and 2013. The power generated from nuclear power plants is significantly higher than power generated from other sources, such as substitute energy, collective energy, hydro energy, and gas energy. 


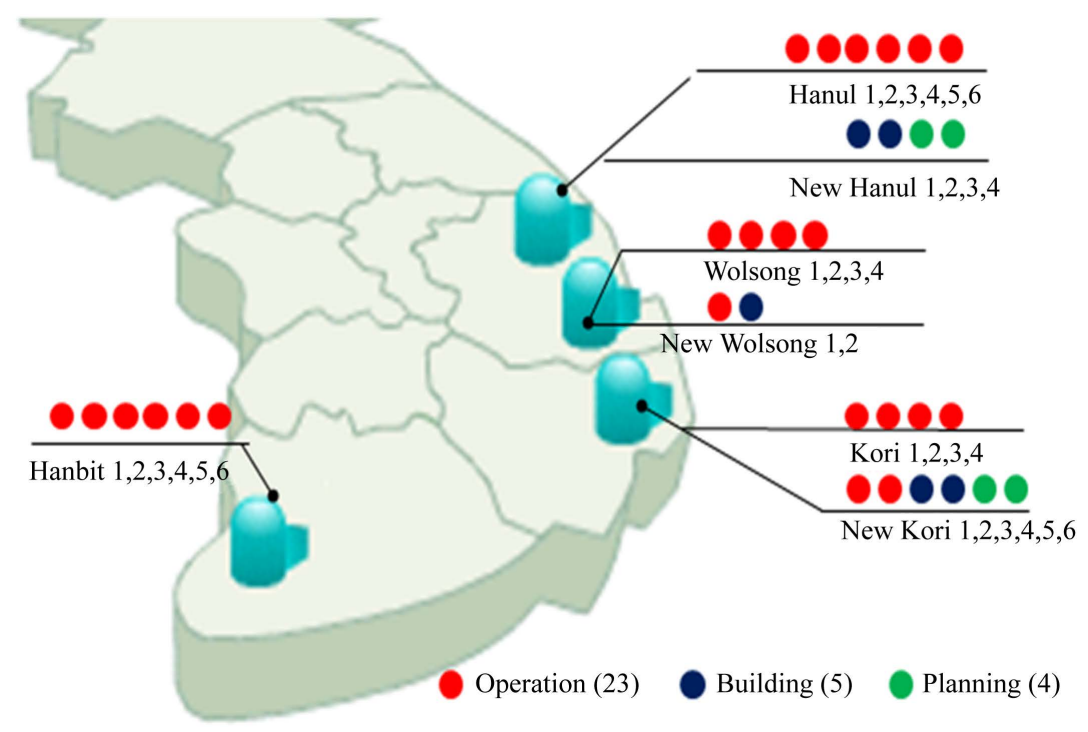

Figure 1. Current state of nuclear power plants in Korea.

Table 1. Power generation performance by nuclear power plant in 2013.

\begin{tabular}{|c|c|c|c|}
\hline \multicolumn{2}{|c|}{ Division } & Power generation (MWh) & Total accumulated power generation (MWh) \\
\hline \multirow{4}{*}{ Kori } & $\# 1$ & $2,657,665$ & $139,885,627$ \\
\hline & $\# 2$ & $4,789,238$ & $153,152,711$ \\
\hline & \#3 & $9,137,086$ & $213,183,941$ \\
\hline & $\# 4$ & $6,886,938$ & $212,056,398$ \\
\hline Sub-total & & $23,470,927$ & $718,278,677$ \\
\hline \multirow{2}{*}{ New Kori } & $\# 1$ & $2,442,559$ & $19,299,310$ \\
\hline & $\# 2$ & $3,734,318$ & $9,437,686$ \\
\hline \multirow[t]{2}{*}{ Sub-total } & & $6,176,877$ & 28,736,996 \\
\hline & $\# 1$ & 0 & $139,681,517$ \\
\hline \multirow{3}{*}{ Wolsong } & \#2 & $4,970,611$ & $96,503,182$ \\
\hline & \#3 & $5,660,527$ & $92,348,908$ \\
\hline & $\# 4$ & $5,557,805$ & $86,867,828$ \\
\hline \multirow{2}{*}{$\begin{array}{l}\text { Sub-total } \\
\text { New Wolsong }\end{array}$} & & $16,188,943$ & $415,401,435$ \\
\hline & $\# 1$ & $3,481,197$ & 8,726,892 \\
\hline \multirow[t]{2}{*}{ Sub-total } & & $3,481,197$ & 8,726,892 \\
\hline & $\# 1$ & $7,192,348$ & $207,232,132$ \\
\hline \multirow{5}{*}{ Hanbit } & $\# 2$ & $6,536,909$ & $197,445,621$ \\
\hline & \#3 & $4,971,540$ & $151,022,128$ \\
\hline & $\# 4$ & $7,961,688$ & $149,189,552$ \\
\hline & $\# 5$ & $8,680,074$ & $95,277,632$ \\
\hline & $\# 6$ & $9,038,969$ & $92,088,004$ \\
\hline \multirow[t]{2}{*}{ Sub-total } & & $44,381,528$ & $892,255,069$ \\
\hline & $\# 1$ & $7,540,925$ & $188,464,632$ \\
\hline \multirow{5}{*}{ Hanul } & $\# 2$ & 7,788,823 & $184,051,303$ \\
\hline & \#3 & $9,200,391$ & $129,718,937$ \\
\hline & $\# 4$ & $3,488,364$ & $109,195,853$ \\
\hline & $\# 5$ & $7,874,761$ & $81,325,558$ \\
\hline & $\# 6$ & $9,191,236$ & $75,655,856$ \\
\hline \multicolumn{2}{|l|}{ Sub-total } & $45,084,500$ & $768,412,139$ \\
\hline \multicolumn{2}{|l|}{ Totals } & $138,783,972$ & 2,831,811,209 \\
\hline
\end{tabular}


Table 2. Trend of power generation by nuclear power plant.

\begin{tabular}{ccccccc}
\hline Division & Hydroelectric $(\mathrm{GWh})$ & Gas $(\mathrm{GWh})$ & Nuclear $(\mathrm{GWh})$ & Group $(\mathrm{GWh})$ & Alternative $(\mathrm{GWh})$ & Total (GWh) \\
\hline 2003 & 6887 & 39,090 & 129,672 & - & - & 322,452 \\
2004 & 5861 & 55,999 & 130,715 & 3553 & 350 & 342,148 \\
2005 & 5189 & 58,118 & 146,779 & 2759 & 404 & 364,638 \\
2006 & 5219 & 68,302 & 148,749 & 2597 & 511 & 381,181 \\
2007 & 5042 & 78,427 & 142,937 & 3084 & 829 & 403,124 \\
2008 & 5561 & 75,809 & 150,958 & 5336 & 1090 & 422,355 \\
2009 & 5641 & 65,274 & 147,771 & 5827 & 1791 & 433,604 \\
2010 & 6472 & 96,734 & 148,596 & 8080 & 3984 & 474,660 \\
2011 & 7831 & 101,702 & 154,723 & 12,429 & 7592 & 496,893 \\
2012 & 7651 & 113,984 & 150,327 & 13,061 & 10,563 & 509,574 \\
2013 & 8483 & 126,576 & 138,784 & 13,846 & 10,760 & 513,464 \\
\hline
\end{tabular}

In addition, the generation amount has been shown to be continuously increasing from 2003 until 2012. The reason for the decrease of generation in 2013 can be identified as the operation stoppage of Wolseong Nuclear Power Plant 1, as indicated in Table 2. In terms of the overseas business performance in the nuclear power plant construction, Korea entered an agreement on the first step operation of and the support of technical maintenance for Guangdong Nuclear Power Plant with China in 1999, and is promoting the unit technology service to China, and technical support to Argentina, Rumania, and Canada. In particular, Korean government spearheaded by Korea Electric Power Corp. (KEPCO) won the bid of UAE nuclear power plant (APR1400 4 unit) for the first time in its history in December 2009. Since the export to UAE, the Korean government and its governmental bodies in charge of nuclear power plant export have cooperated closely to promote the export of nuclear power plants to Vietnam, Saudi, and the Republic of South Africa.

\section{Case Analysis}

\subsection{Construction Summary}

The case analyzed in this study locates in the Middle East, and Figure 2 shows the status of the case placed onsite. Building $1400 \mathrm{MW}$ level for group nuclear power plant and village infrastructure facilities construction, cooling water system construction, and marine structures construction, foundation excavation, backfilling and site preparation and construction in progress that total construction period is 123 months.

\subsection{Construction Duration}

Figure 3 depicts the main construction timeline of nuclear power plant 1 in this study. The timeline consists of a total of 88 months from the order contract to the completion of nuclear power plant 1 . It is revealed that it would take about 58 months from concrete placement in July 2012 to May 2017 to complete the plant. The construction duration of the RCB external wall is shown as 9.5 months, from Apr. 2013 to Jan. 2014.

\subsection{Construction of RCB External Wall}

Figure 4 like the RCB external wall of the case studied was comprised of a total of 18 layers, and the thickness of the wall was 4 foot 6 inches thick. Concrete was placed at the same level shown in Table 3.

The construction duration of the RCB was a total of 282 days, from Apr. 12, 2013 to Jan. 19, 2014. Table 4 indicates the construction duration of one layer of the RCB, from which it can be seen that the duration of one layer averaged 15.6 days. Figure 5 shows the drawing of entry through which a Polar Crane can be placed within the RCB. The duration of the 4th and the 7th layers was extended due to the additional work required to install the equipment hatch. 


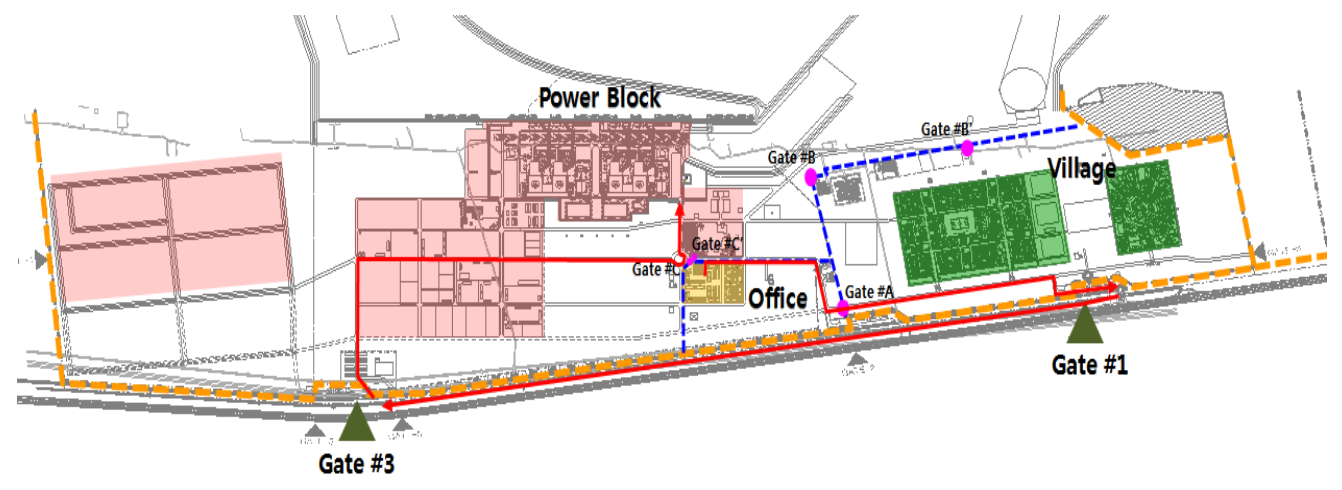

Figure 2. Layout of the case site.

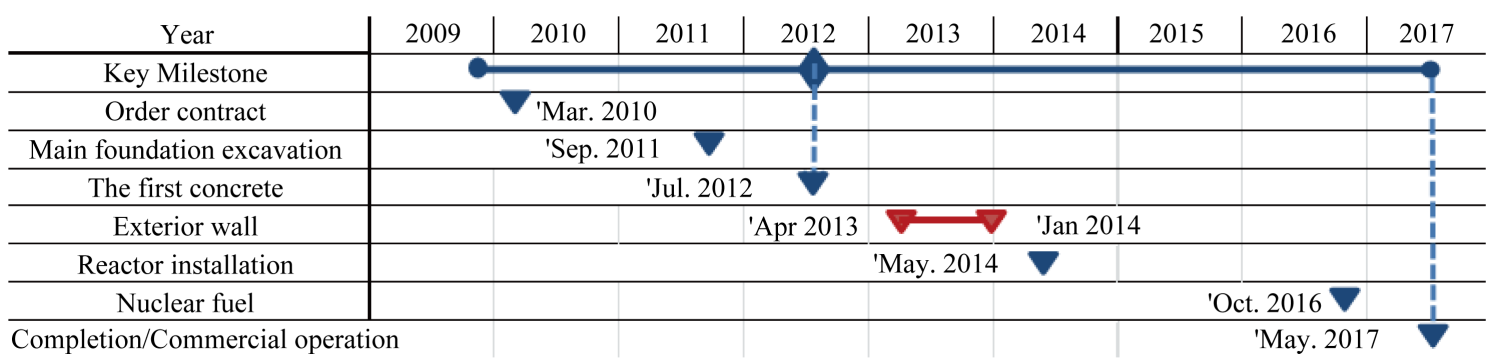

Figure 3. Milestone of nuclear power plant 1.

Table 3. Height of concrete placement per a unit.

\begin{tabular}{cc}
\hline Unit & Placing high (feet) \\
\hline 1st - 2nd & $9^{\prime}$ \\
3rd - 17th & $10^{\prime}$ \\
18th & $7^{\prime}$ \\
\hline
\end{tabular}

Table 4. Construction duration of external wall.

\begin{tabular}{ccc}
\hline External wall & Actual duration & Plan duration \\
\hline 1st & 24 & 24 \\
2nd & 13 & 15 \\
3rd & 12 & 14 \\
4th & 32 & 32 \\
5th & 12 & 13 \\
6th & 13 & 15 \\
7th & 42 & 44 \\
8th & 17 & 19 \\
9th & 9 & 9 \\
10th & 13 & 14 \\
11th & 9 & 9 \\
12th & 9 & 9 \\
13th & 24 & 25 \\
14th & 11 & 12 \\
15th & 12 & 13 \\
16th & 10 & 11 \\
17th & 10 & 10 \\
18th & 10 & 9 \\
Total & 282 & 297 \\
Average & 15.6 & 16.50 \\
\hline
\end{tabular}




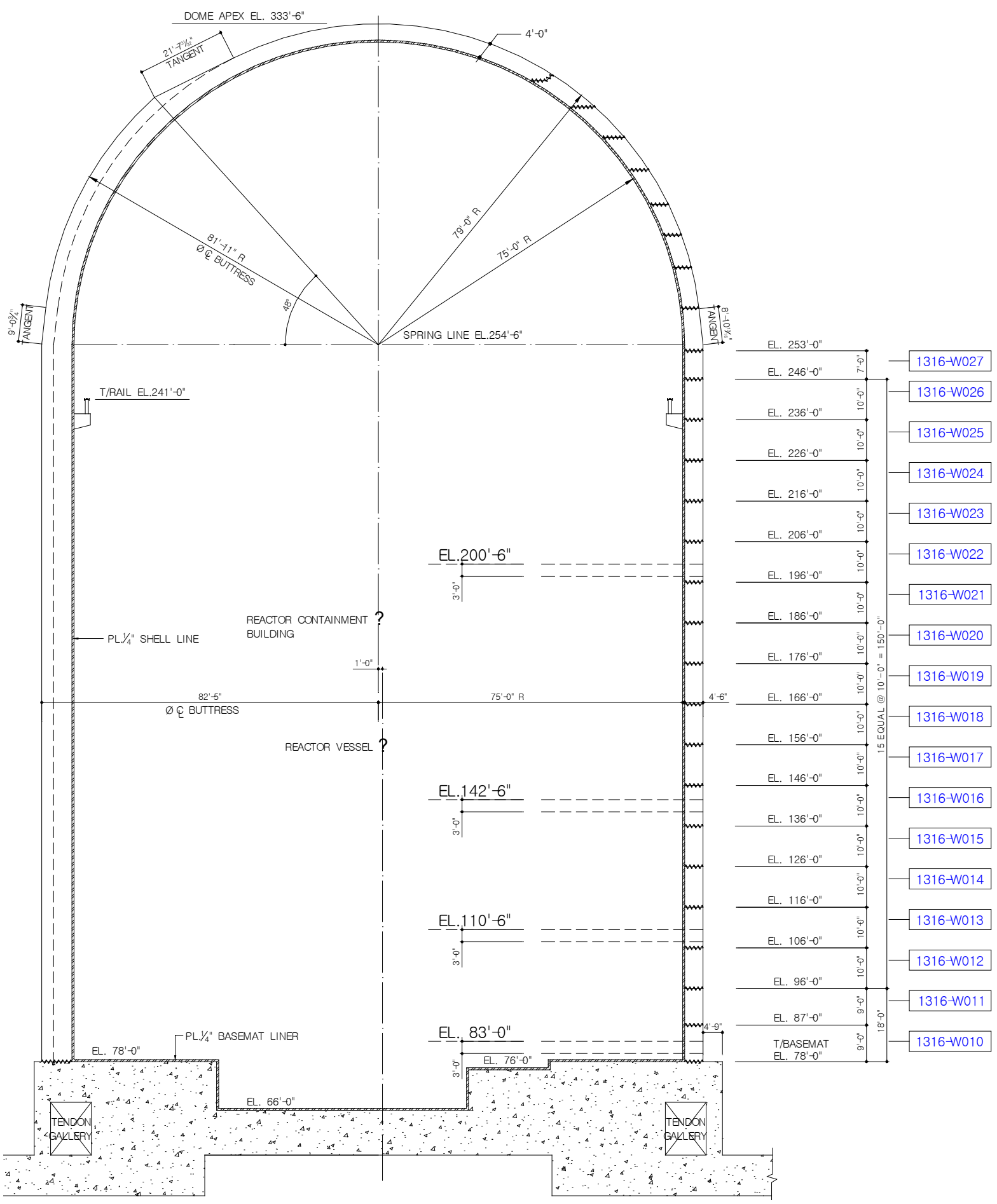

Figure 4. Sectional drawing of the RCB external wall.

\subsection{Construction Procedure of a RCB External Wall}

The external wall construction is carried out when after a containment liner plate (CLP hereinafter) is stalled in $\mathrm{RCB}$, and then sheath is installed, and the external wall formwork is installed according to the construction flow of the external wall like Figure 6. As the external formwork, a general form is used for the 1st and 2nd layers, and a system form is used from the 3rd layer. After the installation of the external wall formwork, rebar, sheath 


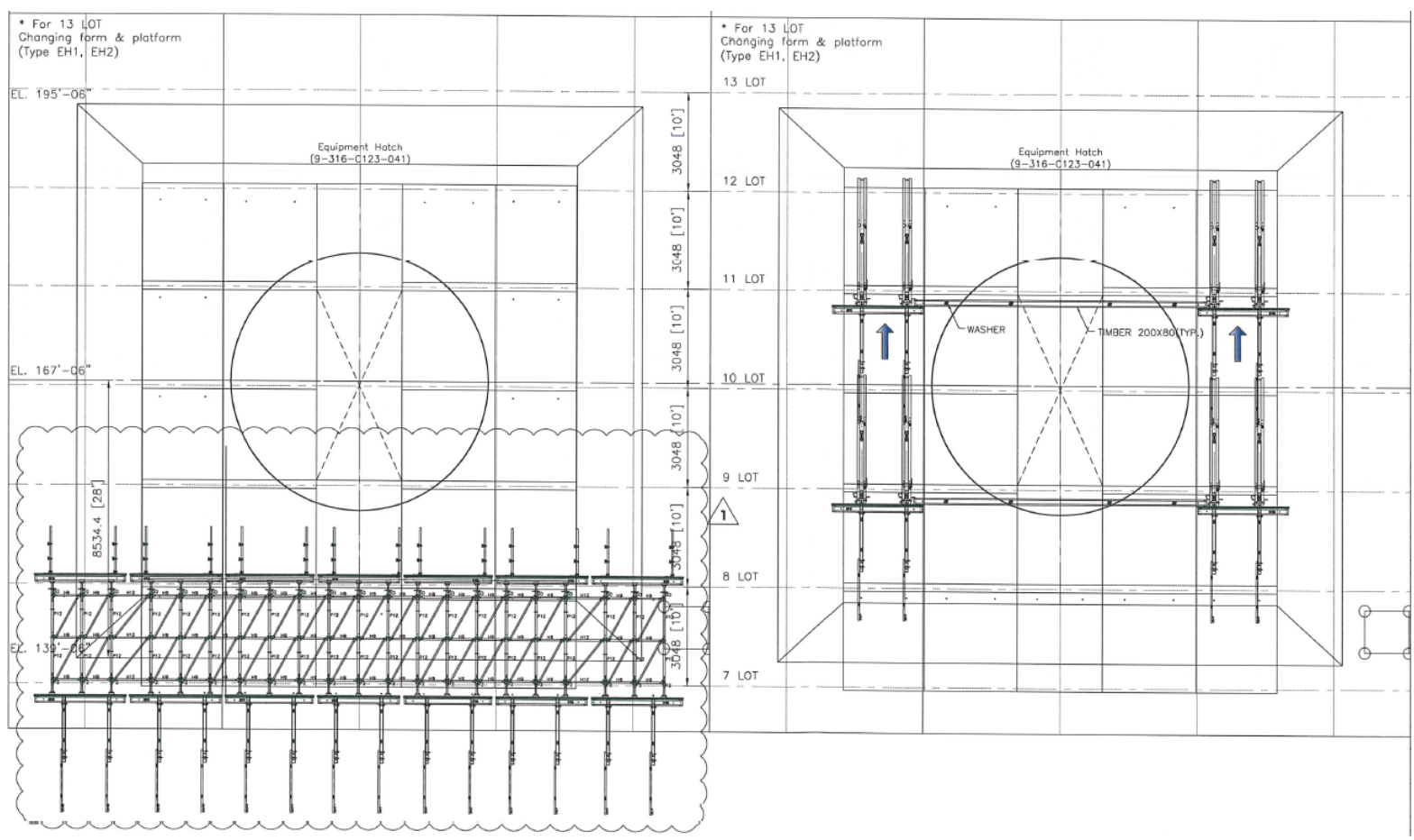

Figure 5. Equipment hatch.

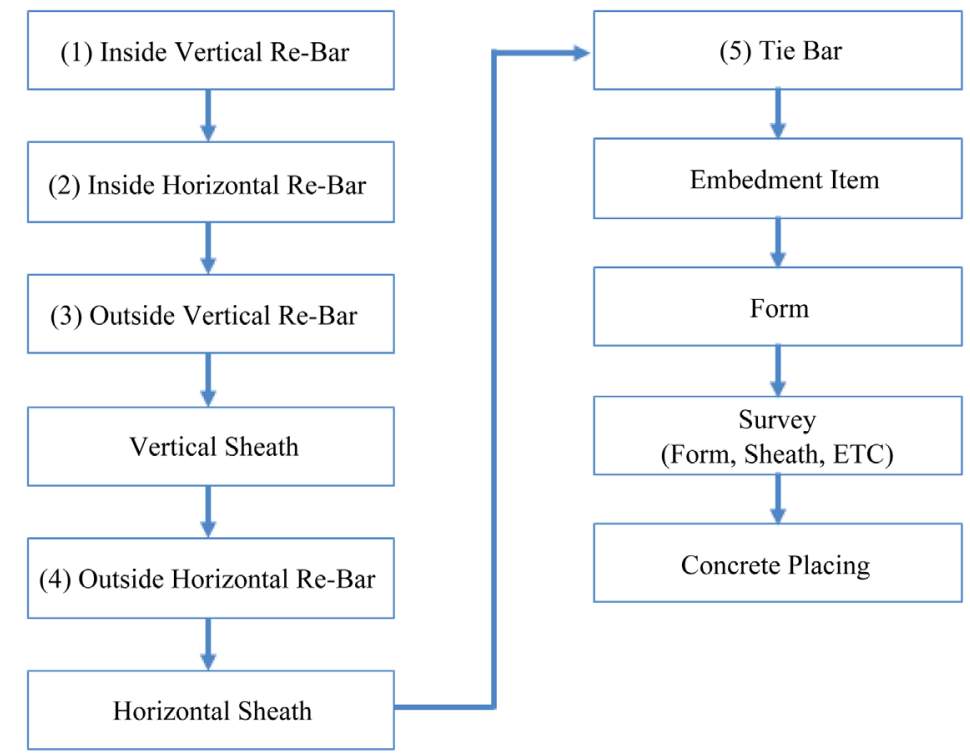

Figure 6. Construction procedure of external wall.

and form are examined through various tests by construction engineer, quality control inspectors, and the KEPCO inspector in charge to check its safety, concrete is placed. Figure 7 shows the layout of rebars in the RCB wall, by which the installation position of rebar can be identified.

Current state of nuclear power plants in Korea, while Figure 2 and Figure 3 show that the construction starts date of plants 1 and 2 were the same. In addition, there was a 10-month difference in construction duration between plant 1 and plant 2. Table 5 indicates the workload of rebar, form, and concrete work of the RCB external wall in the construction site of the case. Table 6 shows the number of laborers input in the formwork, rebar, miscellaneous, concrete and sheath work. From the figure, it appears that about double the number of laborers 


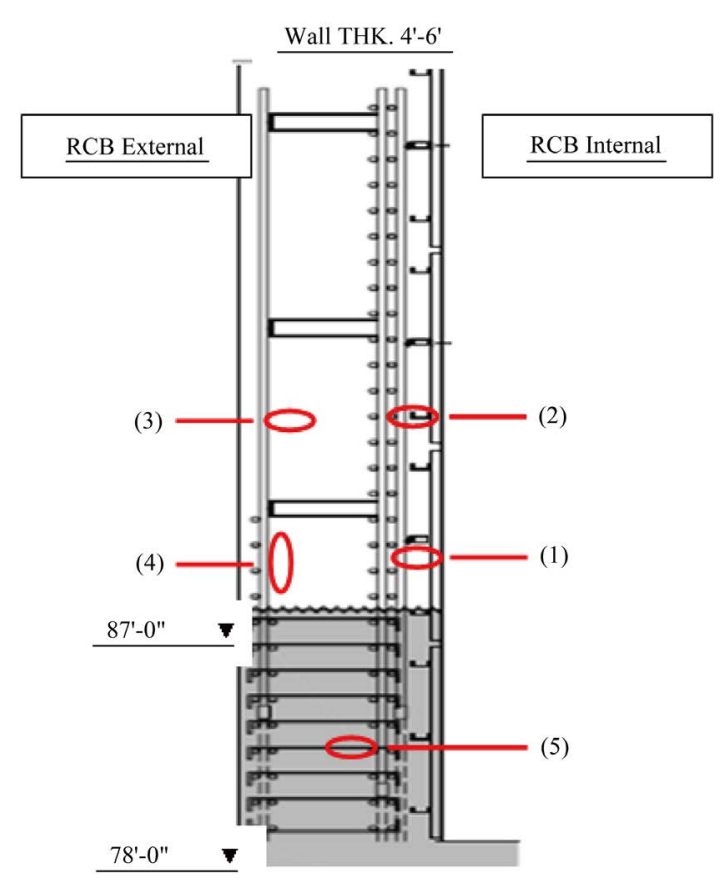

Figure 7. Layout of rebar installation.

Table 5. Scale of workload for the one layer of the external wall.

\begin{tabular}{ccc}
\hline Division & Unit & Per a unit \\
\hline Reinforced & Ton & 184 \\
Form & M2 & 466 \\
Concrete & CY & 842 \\
\hline
\end{tabular}

Table 6. Current state of the number of laborers by work type.

\begin{tabular}{|c|c|c|c|c|c|c|c|c|c|c|c|}
\hline \multirow{2}{*}{\multicolumn{2}{|c|}{ Division }} & \multicolumn{9}{|c|}{2013} & \multirow{2}{*}{$\begin{array}{c}2014 \\
\text { Jan. }\end{array}$} \\
\hline & & Apr. & May & Jun. & Jul. & Aug. & Sep. & Oct. & Nov. & Dec. & \\
\hline \multirow{4}{*}{ Form } & KOR & 2 & 2 & 2 & 2 & 2 & 2 & 2 & 2 & 2 & 2 \\
\hline & TCN & 28 & 22 & 28 & 22 & 22 & 28 & 22 & 28 & 22 & 22 \\
\hline & Sum & 30 & 24 & 30 & 24 & 24 & 30 & 24 & 30 & 24 & 24 \\
\hline & KOR & 4 & 4 & 4 & 4 & 4 & 4 & 4 & 4 & 4 & 4 \\
\hline \multirow[t]{3}{*}{ Reinforced } & TCN & 56 & 46 & 56 & 46 & 46 & 56 & 46 & 56 & 46 & 56 \\
\hline & Sum & 60 & 50 & 60 & 50 & 50 & 60 & 50 & 60 & 50 & 60 \\
\hline & KOR & 2 & 2 & 2 & 2 & 2 & 2 & 2 & 2 & 2 & 2 \\
\hline \multirow{3}{*}{$\begin{array}{l}\text { Miscellaneous } \\
\text { steel }\end{array}$} & TCN & 8 & 8 & 8 & 18 & 18 & 18 & 8 & 8 & 18 & 18 \\
\hline & Sum & 10 & 10 & 10 & 20 & 20 & 20 & 10 & 10 & 20 & 20 \\
\hline & KOR & 5 & 5 & 5 & 5 & 5 & 5 & 5 & 5 & 5 & 5 \\
\hline \multirow[t]{3}{*}{ Concrete } & TCN & 78 & 78 & 78 & 78 & 78 & 78 & 78 & 78 & 78 & 78 \\
\hline & Sum & 83 & 83 & 83 & 83 & 83 & 83 & 83 & 83 & 83 & 83 \\
\hline & KOR & 2 & 3 & 3 & 3 & 3 & 3 & 3 & 3 & 3 & 3 \\
\hline \multirow[t]{2}{*}{ Sheath } & TCN & 8 & 12 & 12 & 12 & 12 & 12 & 12 & 12 & 12 & 12 \\
\hline & Sum & 10 & 15 & 15 & 15 & 15 & 15 & 15 & 15 & 15 & 15 \\
\hline \multicolumn{2}{|c|}{ Total } & 193 & 182 & 198 & 192 & 192 & 208 & 182 & 198 & 192 & 202 \\
\hline
\end{tabular}

KOR: KOREAN; TCN: Third Country Nationality. 
was deployed for rebar work compared with the number for form, miscellaneous, concrete and sheath work.

\section{Discussion of Results}

The construction duration of the case construction project of this study is planned as a total of 123 months to build four nuclear power plants with a 1400 MW generation capacity, a village and infrastructure and other facilities. Of them, only 9.5-month construction duration was presented for the RCB external wall of the 88-month construction duration of one nuclear power plant with 1400 MW generation capacity.

Concrete was placed to be 9 foot 0 inch high for the 1st and 2nd layers, and as 10 foot 0 inch for the 3rd to 17th layers. The difference in the concrete placement is because the system form could not be used in the 1st and 2nd layers. Since a certain level of height should be secured to install the system form, the construction duration of the one layer averaged 24 days, which is longer than the average construction duration. From the 3rd layer, the construction duration averaged 15.6 days because the system form was used, but the construction duration extended in the 4th and 7th layers due to the production of the form and the CLP to make the equipment hatch for the runway girder and rail for the installation of Polar Crane of the nuclear power plant.

In addition, there appeared to be a difference of more than double in the number of laborers input in rebar work compared with that in form, miscellaneous, concrete and sheath work because a two-shift system was run to meet the workload of rebar work, which means there would have been a difference of 15.6 days or more if the two-shift system was not kept.

Therefore, to reduce the construction duration of a nuclear power plant, the construction duration of the RCB external wall was cut by placing concrete higher than the conventional level of the one layer or 10'-0", and by modularizing or pre-constructing the equipment hatch.

\section{Conclusion}

This study analyzed the RCB external formwork, and then suggested the plan to reduce the construction duration of a nuclear power plant. Through the case study in order to reduce the construction duration, formwork process, external wall drawing, construction duration, and the state of input labor information are analyzed. The result is identified that the construction duration is delayed because RCB external wall produces the new form and CLP to make the equipment hatch during the form production process. In addition, it is able to recognize the reduction effect of one layer thereby running parallel with 2 shift reinforcement work. It seems that the formwork construction duration is reduced by so doing higher construction of form height than current $10 \mathrm{ft}$ of placing height. This study contributes to the reduction construction duration plant through improving constructability of the external construction of a nuclear power plant. Future research is going to launch the reduction effect of construction duration according to the height of form placing based on this research.

\section{Acknowledgements}

This work was supported by the Nuclear Power Core Technology Development Program of the Korea Institute of Energy Technology Evaluation and Planning (KETEP), granted financial resource from the Ministry of Trade, Industry \& Energy, Republic of Korea (No.20131520100750).

\section{References}

[1] Bang, C.J., Cho, D.S. and Hur, Y. (2010) Improvement of Competitive Power for NPPs Based on Advanced Construction Technology. Korea Concrete Institute, 22, 40-42.

[2] Kim, J.Y., Bang, C.J., Lee, B.Y. and Kim, S.C. (2013) Analysis of Construction Technology Trends for Nuclear Power Plants Construction with New Construction Technology of Overseas Advanced Reactors. Journal of Architectural Institute of Korea, 33, 757-759.

[3] Organisation for Economic Co-Operation and Develop (2012) 2011 World Energy Outlook. International Energy Agency.

[4] Yang, M.D., Jang, M.H. and Kwon, D.H. (2009) The Trend of Construction Duration Reduction for Nuclear Power Palnt in Domestic and Foreign, and Future Prospects. KPMA2009 Symposium, 279-304.

[5] Lee, D.S., Kim, J.K. and Lee, J.L. (1996) Basic Survey of Constructability Improvement for Nuclear Power Plants. Korea Society of Civill Engineers, 1, 547. 
[6] Cho, Y.S. (2002) A Case Study of Nuclear Power Construction Management. The Society Air-Conditioning and Refrigeration Engineers of Korea, 1-11.

[7] Moon, B.S. (2009) A Study on the Application of EVMS to Nuclear Power Plant Construction Project. Soongsill University Press, Dongjak-gu.

[8] Kim, T.H., Kim, D.J., Kim, M.J., Song, C.Y. and Park, J.B. (2011) Rationalization of Design and Construction for N.P.P Concrete Structures. Korea Society of Civil Engineers, 23, 761-762. 
Scientific Research Publishing (SCIRP) is one of the largest Open Access journal publishers. It is currently publishing more than 200 open access, online, peer-reviewed journals covering a wide range of academic disciplines. SCIRP serves the worldwide academic communities and contributes to the progress and application of science with its publication.

Other selected journals from SCIRP are listed as below. Submit your manuscript to us via either submit@scirp.org or Online Submission Portal.
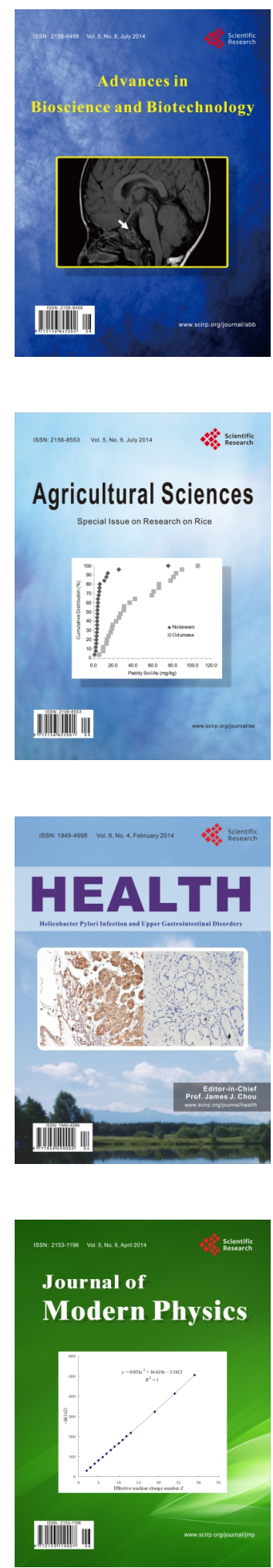
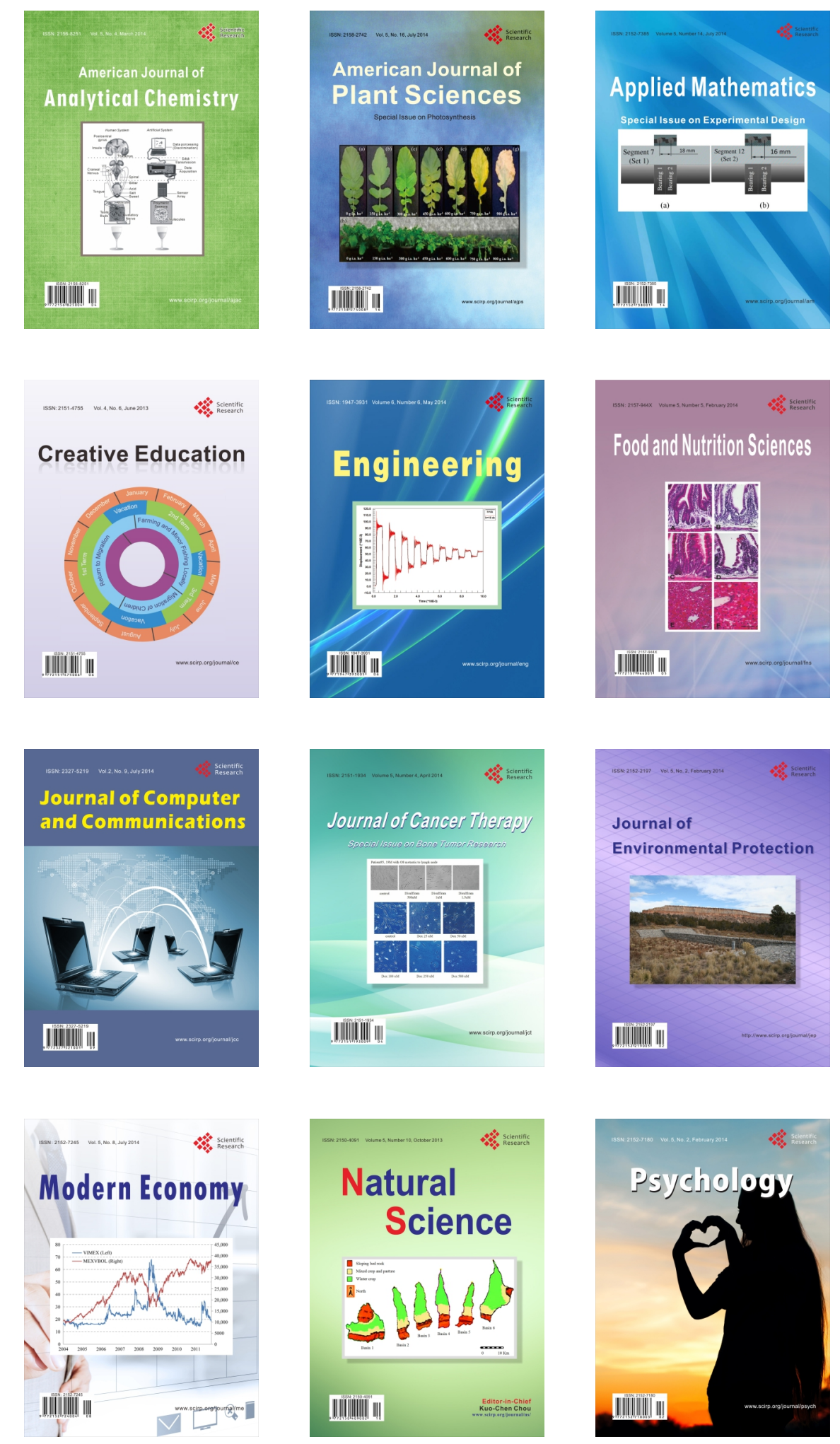